\title{
Pengenalan Tanda Tangan Menggunakan Algoritme VFI5 Melalui Praproses Wavelet
}

\section{Hand-Written Signature Recognition using VFI5 Algorithm with Wavelet Preprocessing}

\author{
FATHONI ARIEF MUSYAFFA, AZIZ KUSTIYO*
}

\begin{abstract}
Abstrak
Tanda tangan merupakan salah satu objek biometrik yang mudah diperoleh, baik melalui kertas maupun peralatan elektronik. Meskipun demikian, biometrik tanda tangan masih menjadi topik riset yang menantang. Tantangan dalam biometrik tanda tangan ini ialah antara lain karena variasi dalam kelas yang besar, tingkat universality dan permanence yang rendah, serta adanya kemungkinan serangan pemalsuan tanda tangan. Penelitian ini menggunakan metode pengenalan tanda tangan secara offline. Pengenalan tanda tangan dilakukan dengan menggunakan algoritme klasifikasi Voting Feature Interval 5. Sebelum dilakukan klasifikasi pada citra tanda tangan yang berdimensi 40 x 60 piksel, dilakukan praproses untuk mereduksi ukuran citra. Reduksi yang digunakan adalah reduksi dimensi melalui transformasi wavelet dengan lima level dekomposisi. Hasil yang diperoleh dari penelitian ini ialah bahwa sampai dengan level dekomposisi ketiga, dengan dimensi fitur sekitar $1.5 \%$ dari seluruh fitur, diperoleh akurasi minimum $90 \%$.
\end{abstract}

Kata kunci: biometrik, klasifikasi, tanda tangan, voting feature interval

\begin{abstract}
Signature is one of the biometric objects that are easily available, either via paper or electronic equipment. However, biometric signature is still a challenging research topic. The challenges in biometric signature are partly because of its variations in the large class, its low universality and permanence levels, and the possibility of forgery signature attack. This study utilized offline signature recognition. The signature recognition was done by using classification Voting Feature Interval 5 algorithm. Before the classification on the signature image in $40 x 60$ pixels dimension was conducted, a pre-processing was done to reduce the size of the image. The used reduction was the reduction of dimensions through the use of wavelet transform with five level of decomposition. The result obtained from this study wasthat up to a third level of decomposition, with feature dimension of about $1.5 \%$ of the whole features, obtained a minimum accuracy of $90 \%$.
\end{abstract}

Keywords: biometrics, classification, signatures, voting feature interval

\section{PENDAHULUAN}

Biometrik merupakan ilmu pengetahuan yang membangun identitas seseorang berdasarkan pada sifat-sifat fisik, kimiawi, ataupun kebiasaan seseorang. Sistem biometrik dapat menggunakan ciri fisik (physical traits) maupun tingkah laku (behavioral traits). Contoh ciri fsik ialah antara lain sidik jari, iris, wajah, dan bentuk geometris tangan, sedangkan contoh ciri tingkah laku misalnya tanda tangan, pola penekanan keyboard, dan gaya berjalan (Ross et al. 2006). 
Tanda tangan merupakan salah satu objek biometrik yang mudah diperoleh, baik melalui kertas maupun peralatan elektronik seperti tablet personal computer, layar sentuh dan personal digital assistant. Meskipun demikian, biometrik tanda tangan masih menjadi topik riset yang menantang. Tantangan dalam biometrik tanda tangan ini ialah antara lain variasi dalam kelas yang besar, tingkat universality dan permanence yang rendah, serta adanya kemungkinan serangan pemalsuan tanda tangan (Jain et al. 2008).

Metode pengenalan tanda tangan dapat diklasifikasikan berdasarkan informasi masukan tanda tangan menjadi dua kategori, online dan offline. Metode pengenalan tanda tangan online merujuk pada penggunaan fungsi-fungsi waktu dalam proses penandatanganan secara dinamis (misalnya lintasan posisi atau penekanan). Metode pengenalan tanda tangan offline merujuk pada penggunaan gambar statis dari tanda tangan (Jain et al. 2008).

Penelitian yang terkait dengan pengenalan tanda tangan secara offline telah dilakukan oleh Riadi (2001) menggunakan jaringan syaraf tiruan (JST) propagasi balik dengan akurasi tertinggi sebesar 99\%. Pada tahap pelatihan JST, perlu ditentukan representasi input dan output yang tepat serta pencarian kombinasi nilai-nilai parameter JST, seperti nilai toleransi galat, laju pembelajaran, fungsi aktivasi, dan jumlah neuron lapisan tersembunyi yang optimal. Pencarian kombinasi nilai-nilai parameter JST yang optimal memerlukan waktu yang cukup banyak.

Berbeda dengan JST, algoritme VFI5 merupakan algoritme klasifikasi yang dalam proses pelatihannya tidak memerlukan pencarian kombinasi nilai-nilai parameter. VFI5 merupakan algoritme supervised learning yang bersifat non-incremental sehingga seluruh contoh dalam data training diproses sekali dalam satu waktu (Demiroz 1997). Kelebihan algoritme VFI5 adalah prediksi yang akurat, pelatihan dan waktu yang dibutuhkan untuk melakukan klasifikasi cukup singkat, bersifat robust terhadap training dengan data yang memiliki noise dan nilai fitur yang hilang, dapat menggunakan bobot fitur, serta dapat memberikan model yang mudah dipahami manusia (Güvenir 1998).

Praproses dilakukan untuk mereduksi ukuran citra. Citra yang memiliki ukuran $m \times n$ piksel misalnya, akan memiliki $m \times n$ fitur pada algoritme VFI5 sehingga komputasi yang dilakukan menjadi lebih banyak dan diperlukan proses reduksi. Reduksi yang digunakan dalam penelitian ini adalah reduksi dimensi melalui transformasi wavelet. Dibandingkan dengan metode reduksi PCA, reduksi dimensi menggunakan wavelet memiliki efisiensi komputasi yang lebih baik (Agarwal et al. 2005).

Transformasi wavelet untuk mereduksi dimensi telah dilakukan pada pengenalan citra wajah oleh Anjum dan Javed (2006). Pada penelitian tersebut, hanya low pass filter yang digunakan karena diasumsikan low frequency memberikan banyak kontribusi dalam merepresentasikan informasi citra wajah.

Penelitian ini bertujuan melakukan pengenalan tanda tangan dengan menggunakan algoritme VFI5 dengan praproses transformasi wavelet. Selanjutnya dilakukan analisis kinerja pengenalan tanda tangan menggunakan algoritme VFI5 dan pengaruh dekomposisi wavelet terhadap akurasi yang diperoleh.

\section{METODE}

Ada beberapa tahap yang dilakukan dalam proses klasifikasi citra tanda tangan dengan menggunakan praproses wavelet (Gambar 1). Data yang digunakan dalam penelitian ini berasal dari data pada penelitian Setia (2007). Pada penelitian tersebut, data tanda tangan dikumpulkan di atas kertas dan proses digitalisasi dilakukan dengan menggunakan scanner menjadi file citra 300 dpi format BMP dan mode RGB. Citra tanda tangan ini selanjutnya dikonversi menjadi citra 8 bit dengan format PCX berukuran $40 \times 60$ piksel. Posisi yang dihasilkan oleh citra tanda tangan masih tidak teratur dan acak. Oleh karena itu, penyuntingan citra tanda tangan dilakukan agar citra tanda tangan yang diperoleh bersifat teratur. Tahap 


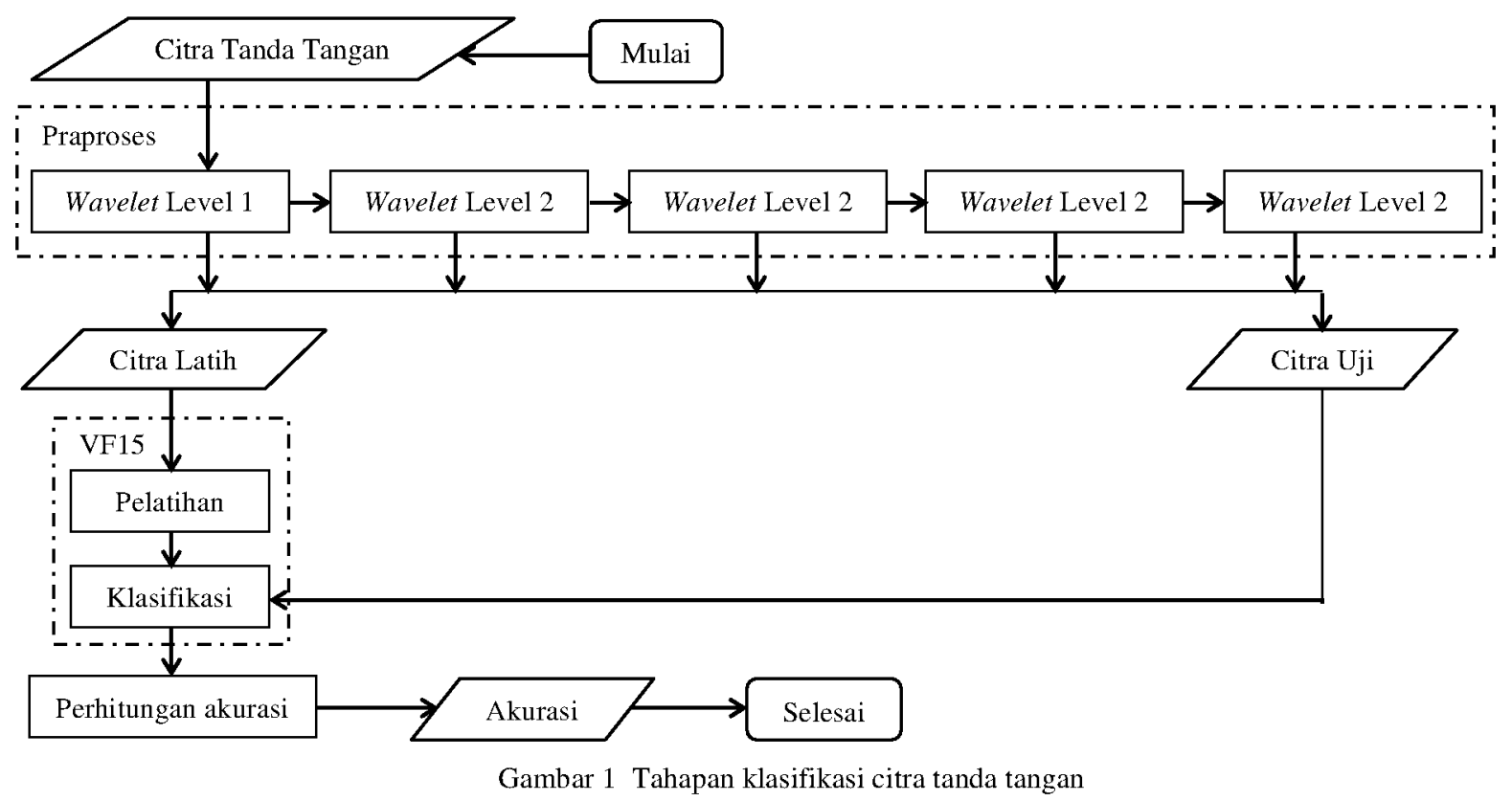

selanjutnya dari proses pengambilan citra adalah cropping. Hal ini dilakukan untuk menghilangkan bagian di luar pola yang bukan merupakan pola tanda tangan.

Citra tanda tangan tersebut berasal dari tanda tangan 10 orang, diberi kode kelas $p, q, r$, $s, \ldots, y$, dan setiap orang memberikan tanda tangan sebanyak 10 kali. Semua citra tanda tangan yang digunakan dalam penelitian ini melalui praproses transformasi wavelet. Selanjutnya, citra latih dan citra uji diklasifikasikan menggunakan algoritme VFI5. Citra tanda tangan yang akan diproses dengan algoritme VFI5 direduksi terlebih dahulu menggunakan transformasi wavelet. Hal ini dilakukan agar fitur yang dihitung tidak terlalu banyak sehingga proses komputasi lebih mudah dan cepat.

Citra tanda tangan yang diproses menggunakan transformasi wavelet akan mengalami penurunan banyak fitur hingga 75\% dari banyak fitur semula. Transformasi wavelet dilakukan hingga 5 level. Setelah melalui transformasi wavelet, diperoleh 4 citra yang memiliki dimensi baru, yakni citra pendekatan, citra detail horizontal, citra detail vertikal, dan citra detail diagonal.

Data dibagi ke dalam dua bagian, yaitu data latih dan data uji. Data latih digunakan untuk memberikan supervised learning pada algoritme VFI5, sedangkan data uji digunakan untuk menguji ketepatan hasil klasifikasi yang dilakukan oleh algoritme VFI5. Perbandingan antara data latih dan data uji yang digunakan dalam percobaan ini ialah 3:2. Hal ini berarti terdapat 6 citra latih dan 4 citra uji untuk tiap-tiap kelas.

Dua proses dalam algoritme VFI5 ialah pelatihan dan klasifikasi. Pada proses pelatihan, dibuat interval untuk setiap fitur yang akan menentukan nilai vote fitur untuk setiap kelas. Kelas dari setiap data uji diprediksi berdasarkan pada nilai total vote pada proses klasifikasi. Kelas yang memiliki nilai total vote tertinggi dijadikan kelas prediksi data uji tersebut. Tingkat akurasi yang dicapai algoritme klasifikasi VFI5 dihitung menggunakan rumus:

$$
\text { tingkat akurasi }=\frac{\sum \text { data uji benar diklasifikasi }}{\sum \text { total data uji }} \times 100 \%
$$

\section{HASIL DAN PEMBAHASAN}

\section{Kinerja Algoritme VFI5 pada Tiap Level Dekomposisi}

Dimensi citra sebelum direduksi ialah 40 × 60 piksel dengan dimensi fitur sebesar 6400. Akurasi klasifikasi citra tersebut ialah sebesar 97.5\%. Data diproses menggunakan 
transformasi wavelet Haar hingga level ke-5. Setiap naik satu level dekomposisi, dimensi fitur berkurang sebanyak $75 \%$ sehingga pada level ke-3 dimensi fitur hanya sebesar 40 dari semula 2400 (Tabel 1).

Dengan meningkatnya level dekomposisi, terjadi penurunan akurasi. Namun demikian akurasi pada dekomposisi level 3 dengan dimensi fitur sebesar 40 masih tinggi, yaitu mencapai $90.0 \%$. Akurasi menurun drastis pada dekomposisi level 4 menjadi 65\% (Tabel 2). Hal ini kemungkinan disebabkan oleh makin berkurangnya dimensi fitur menjadi 12 pada level 4. Putra (2009) melaporkan level dekomposisi justru meningkat dengan nilai akurasi tertinggi pada dekomposisi level 2 dan level 3 sebesar $98.0 \%$.

Penelitian Riadi (2001) yang menggunakan keseluruhan 2400 fitur sebagai input dalam JST menghasilkan akurasi tertinggi sebesar 99\%. Jika citra tanda tangan yang berukuran $40 \times$ 60 piksel direduksi menjadi $30 \times 45$ piksel dan disegmentasi sebanyak 45 segmen dengan setiap segmen terdiri atas vektor observasi berukuran 30, dengan menggunakan 8 hidden state, diperoleh rata-rata akurasi sebesar $75 \%$. Setelah dilakukan dekomposisi wavelet level 1 , terdapat 600 fitur sebagai input dalam algoritme VFI5 dan diperoleh akurasi sebesar $97.5 \%$.

Jika dibandingkan dengan hasil percobaan tanpa reduksi yang memiliki 2400 fitur dengan hasil percobaan melalui reduksi wavelet level 1 yang memiliki 600 fitur, diperoleh kesamaan akurasi sebesar 97.5\%. Meskipun demikian, banyak fitur pada percobaan yang telah melalui reduksi telah berkurang hingga $75 \%$.

\section{Kinerja Algoritme VFI5 pada Tiap Kelas}

Pada kelas $p$, seluruh citra pada tiap level dapat diklasifikasikan dengan benar. Pada kelas $q$ dan $y$, akurasi sebesar $100 \%$ hanya diperoleh pada level 1. Secara umum sampai dengan dekomposisi level 2, hampir semua kelas mencapai akurasi 100\% (Gambar 2).

\section{Kinerja Algoritme VFI5 tanpa Kelas $p$}

Pada percobaan selanjutnya, eliminasi dilakukan pada kelas-kelas yang memiliki nilai rata-rata akurasi tertinggi pada semua level dekomposisi, yaitu kelas $p$. Dekomposisi level 1 sampai dengan level 3 menghasilkan akurasi minimum $90 \%$.

Pada percobaan eliminasi kelas $p$ untuk level 1 rata-rata akurasi yang diperoleh oleh semua kelas dengan menghilangkan kelas $p$ mencapai 100\%. Dengan demikian, peningkatan akurasi untuk kelas $y$ ialah sebesar 25\%. Pada percobaan eliminasi kelas $p$ untuk level 2, terjadi penurunan akurasi untuk kelas $v$ sebesar $25 \%$ menjadi $75 \%$ dan peningkatan akurasi sebesar $25 \%$ untuk kelas y menjadi $100 \%$ jika dibandingkan dengan percobaan level 2 menggunakan seluruh kelas. Pada percobaan eliminasi kelas $p$ untuk level 3, kelas $r$ dan kelas $t$ mengalami penurunan akurasi menjadi $75 \%$, berkurang $25 \%$ dari akurasi percobaan sebelumnya dibandingkan dengan akurasi menggunakan data pelatihan seluruh kelas di level 3. Meskipun demikian, kelas y justru mengalami kenaikan nilai akurasi sebesar $25 \%$.

Dari ketiga percobaan tersebut, kinerja algoritme VFI5 mengalami perubahan dengan adanya perubahan banyaknya kelas. Di samping itu, eliminasi kelas $p$ menghasilkan peningkatan akurasi kelas $y$.

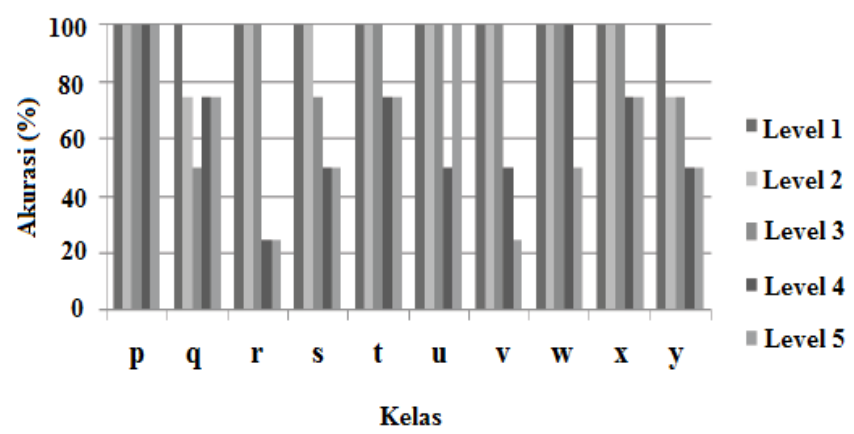

Gambar 2 Akurasi pada setiap level dekomposisi untuk tiap kelas 


\section{Algoritme VFI5 dengan Menggunakan Data Latih yang Berbeda}

Pada level 1, 2, 3, dan 5 akurasi menurun menjadi berturut-turut 95.0, 90.0, 87.5, dan $52.5 \%$. Penurunan akurasi paling besar terjadi pada level 5, yakni sebesar 10\%. Pada level 4, justru terjadi kenaikan akurasi sebesar $2.5 \%$ dibandingkan dengan percobaan dengan kombinasi data ke-1, 2, 3, 4, 5, 6 sebagai data latih dan data ke-7, 8, 9, 10 sebagai data uji (Tabel 3).

\section{Waktu Pemrosesan}

Perhitungan waktu yang diperlukan untuk mengklasifikasikan citra tanda tangan dan hasil perhitungan menunjukkan kecenderungan menurunnya waktu pelatihan dan pengujian sekitar seperempat hingga sepertiga dari level dekomposisi sebelumnya (Tabel 4).

Tabel 1 Ukuran dimensi dan banyak fitur pada dekomposisi wavelet

\begin{tabular}{ccc}
\hline Level dekomposisi & Dimensi citra & Dimensi fitur \\
\hline 1 & $20 \times 30$ & 600 \\
2 & $10 \times 15$ & 150 \\
3 & $05 \times 08$ & 040 \\
4 & $03 \times 04$ & 012 \\
5 & $02 \times 02$ & 004 \\
\hline
\end{tabular}

Tabel 2 Akurasi algoritme VF15 dengan dan tanpa dekomposisi wavelet

\begin{tabular}{cc}
\hline Level dekomposisi & Akurasi (\%) \\
\hline $0^{*}$ & 97.5 \\
1 & 97.5 \\
2 & 95.0 \\
3 & 90.0 \\
4 & 65.0 \\
\hline *Tanpa dekomposisi &
\end{tabular}

Tabel 3 Akurasi level dekomposisi dengan menggunakan data latih dan data uji yang berbeda

\begin{tabular}{cc}
\hline Level dekomposisi & Akurasi $(\%)$ \\
\hline 1 & 95.0 \\
2 & 90.0 \\
3 & 87.5 \\
4 & 67.5 \\
5 & 52.5 \\
\hline
\end{tabular}

Tabel 4 Waktu pemrosesan tiap level dekomposisi

\begin{tabular}{cccc}
\hline Level & Dimensi fitur & $\begin{array}{c}\text { Training } \\
\text { (detik) }\end{array}$ & $\begin{array}{c}\text { Testing } \\
\text { (detik) }\end{array}$ \\
\hline 1 & 600 & 8.266 & 2.375 \\
2 & 150 & 2.250 & 0.672 \\
3 & 040 & 0.656 & 0.187 \\
4 & 012 & 0.219 & 0.062 \\
5 & 004 & 0.078 & 0.031 \\
\hline
\end{tabular}

\section{SIMPULAN}

Kinerja penggabungan antara reduksi dimensi wavelet dan algoritme klasifikasi VFI5 cukup baik untuk digunakan dalam pengenalan citra tanda tangan. Jika dibandingkan antara klasifikasi tanpa melalui reduksi dimensi menggunakan wavelet dan klasifikasi melalui 
reduksi dimensi menggunakan wavelet untuk dekomposisi level 1, diperoleh rata-rata akurasi yang sama, dengan pengurangan dimensi sebanyak $75 \%$.

Akurasi bernilai minimum $90 \%$ jika dekomposisi wavelet yang digunakan berada pada level 1, 2, dan 3. Nilai akurasi ini akan berubah ketika dilakukan perubahan komposisi data latih dan data uji maupun perubahan banyaknya kelas. Selain itu, seiring meningkatnya level dekomposisi wavelet, fitur semakin berkurang dan akurasi yang diperoleh semakin rendah.

Penelitian selanjutnya dapat dilakukan dengan menambahkan noise pada citra tanda tangan yang digunakan. Selain itu, dapat dilakukan verifikasi tanda tangan dengan menggunakan metode reduksi dimensi transformasi wavelet dan algoritme klasifikasi VFI5 dan menganalisis kemiripan fitur menggunakan multidimensional scaling.

\section{DAFTAR PUSTAKA}

Agarwal A, El Ghazawi T, Moigne LE, Joiner J. 2005. An application of wavelet based dimension reduction to AIRS data. Earth-Sun System Technology Conference, ESTC'05; 2005 Jun 27-30; Adelphi, US. Maryland (US): NASA. hlm 4.

Anjum MA, Javed MY. 2006. Face images dimension reduction using wavelets and decimation algorithm. Proceedings of the 2006 International Conference on Image Processing, Computer Vision and Pattern Recognition (IPCV 2006); Las Vegas (US), 2006 Jun 26-29. hlm 397- 402.

Demiröz G. 1997. Non-incremental classification learning algorithms based on voting feature intervals [tesis]. Ankara (TR): Bilkent Univ.

Güvenir HA. 1998. A classification learning algorithm robust to irrelevant features. Di dalam: Giunchiglia F, editor. Artifcial Intelligence: Methodology, Systems Applications. Proceeding of AIMSA '98; Sozopol, BG. 1998 Sep 21-23. Sozopol (BG): SpringerVerlag. hlm 281-290.

Jain AK, Flynn P, Ross AA. 2008. Handbook of Biometrics. New York (US): Springer.

Putra ID. 2009. Identifikasi tanda tangan menggunakan probabilistic neural networks (PNN) dengan praproses menggunakan transformasi wavelet [skripsi]. Bogor (ID): Institut Pertanian Bogor.

Riadi. 2001. Jaringan syaraf tiruan untuk pengenalan tanda tangan [skripsi]. Bogor (ID): Institut Pertanian Bogor.

Ross AA, Nandakumar A, Jain AK. 2006. Handbook of Multibiometrics. New York (US): Springer Science.

Setia API. 2007. Identifikasi tanda tangan menggunakan model markov tersembunyi [skripsi]. Bogor (ID): Institut Pertanian Bogor. 